\title{
Museus e Centros de Ciência na esteira da Diversidade e da Cidadania
}

\author{
Denise C. Studart \\ Museu da Vida, Casa de Oswaldo Cruz, Fiocruz
}

\begin{abstract}
RESUMO: No presente artigo, faremos, inicialmente, uma breve revisão sobre o desenvolvimento dos museus de ciência desde a Era Moderna, procurando refletir sobre o seu lugar no sistema educativo-cultural e de produção de conhecimento. Em seguida, discutiremos o papel dessas instituições no mundo contemporâneo e o quanto são capazes de articular educação, divulgação científica e história no contexto do museu, sem perder de vista o compromisso social.
\end{abstract}

PALAVRAS-CHAVE: Museus - Ciência - Museologia - Educação Não Formal - Divulgação científica

ABSTRACT: In this paper, we will make, initially, a brief review on the development of science museums since the modern era, trying to contemplate their place in the educational and cultural systems and knowledge production. Next, we will discuss the role of these institutions (including science centres) in the contemporary world and how they are able to articulate education, popularization of science and history within the museum context, without losing sight of the social commitment.

KEYWORDS: Museums - Science - Museology - Informal Education - Popularization of science

Os museus são, por excelência, locais de história e estórias, de observação e interação, de reflexão e aprendizagem. Não importa a tipologia de um museu arte, ciência, tecnologia, antropologia, história -, diversas histórias podem ser narradas: do passado (outras épocas, povos e civilizações, suas maneiras de viver e pensar) e do mundo contemporâneo do qual fazemos parte (formas de expressão artísticas e culturais, novas descobertas científicas, etc.). Os museus são espaços simbólicos, muitas vezes mágicos e surpreendentes, que têm a qualidade de oferecer uma experiência ao mesmo tempo educativa e de lazer.

No presente artigo, faremos, inicialmente, uma breve revisão sobre o desenvolvimento dos museus de ciência desde a Era Moderna, procurando refletir sobre o seu lugar no sistema educativo-cultural e de produção de conhecimento. Em seguida, discutiremos o papel dessas instituições (incluindo aqui os centros de ciência) no mundo contemporâneo e o quanto são capazes de articular educação, 
divulgação científica e história no contexto do museu, sem perder de vista o compromisso social.

\section{Museus de Ciência e Técnica nos séculos XVIII e XIX: suportes de estudo, difusão e instrução.}

Em artigo sobre o caráter público dos museus, Valente (2003) relata que, no século XVIII, intelectuais, inspirados pelo espírito enciclopedista, conclamavam pela necessidade de colocar as coleções "a serviço da educação do povo", como suporte de demonstração, estudo e difusão. Nesse contexto, o Estado deveria ser o "tutor" de todo o patrimônio, voltado para a "história nacional" e a "instrução". Na França, um exemplo é o Conservatoire des Arts et Metiers, criado em 1794, para receber as máquinas e instrumentos inventados no país:

\footnotetext{
Essa instituição, moldada pelo enciclopedismo e pelo iluminismo, era portadora das idéias dos projetos revolucionários. Trazia com ela a preocupação essencial desse momento da história dos museus: a vontade de se apropriar, coletivamente, do patrimônio julgado útil a todos. (Valente, 2003:32)
}

O Conservatoire des Arts et Metiers, juntamente com outros museus semelhantes (por exemplo, o Franklin Institute, nos EUA, criado em 1824), funcionavam como "verdadeiras virtrines para a insdústria": "A ideia de educar o cidadão comum (educação de massa) e fazer com que o público conhecesse e 'experimentasse' o progresso científico e tecnológico colocavam-se como objetivos para essas instituições" (Cazelli et al., 2003:87).

Outros importantes museus de ciência também foram criados no final do século XVIII e durante o XIX em toda Europa e EUA, como o Museum National d'Histoire Naturalle, em Paris (1793), a Academy of Natural Sciences, em Filadelfia (1812) e o 
Natural History Museum, em Londres (1881), compartilhando os mesmos ideais de instrução e pesquisa.

Lopes (2003:77) enfatiza que, no século XIX, os museus participavam ativamente do movimento educacional da época e eram reconhecidos como "agentes" desse movimento, juntamente com as universidades e as sociedades acadêmicas. A questão educacional aparecia como algo estruturador de toda a nova sociedade que se implantava, com a queda das monarquias e a ascensão da burguesia. A educação era vista como signo da modernidade. As exposições dos museus de ciência nos séculos XVIII e XIX tinham uma clara intenção "normatizadora e civilizadora" (Cazelli et al., 2003: 87, apud Kuhlmann Jr., 2001:9).

Em Glasgow, no século XIX, a palavra "cientista" foi cunhada durante criação da Associação Britânica para o Progresso da Ciência. Temas científicos começaram a apresentar um aspecto mais público, conforme suas conseqüências práticas se tornavam mais evidentes no cotidiano (Primon et al., 2000). Nesse período, as publicações tornam-se mais especializadas e freqüentes, já demonstrando uma intenção de difusão das ideias e descobertas científicas.

A valorização de grupos sociais como o dos cientistas e artistas teve na burguesia o seu maior público. E apesar do desejo dos museus servirem ao "povo", será a burguesia e alguns grupos seletos que irão usufruir as instituições museológicas nesse período. Como nos conta Valente, até a primeira década do século $\mathrm{XX}$, os museus de arte não se empenhariam na democratização das exposições: "o acesso do grande público só ocorria aos domingos e, por vezes, um dia na semana [...] Na realidade, a função social da instituição foi a de integrar a burguesia que aspirava alcançar a aristocracia" (Valente, 2003:33). Ou seja, os museus, nessa época, serviam, principalmente, a uma burguesia que almejava aos valores aristocratas e seus símbolos de poder, e a artistas e cientistas que procuravam o museu como fonte de estudo. 
No Brasil, ao final do século XIX, a República deu oportunidade às províncias de constituirem seus próprios quadros institucionais acadêmicos. Nesse período, proliferaram pelo país escolas de engenharia, faculdades de medicina, museus de história natural e institutos ligados à saúde. Segundo Dantes (2005), as instituições de maior prestígio nesse momento da história brasileira foram as que atuaram na área de saúde pública. Alguns museus, criados ainda no Império, como o Horto (posteriormente denominado Jardim Botânico do Rio de Janeiro), criado em 1808; o Museu Real (posteriormente Museu Nacional de História Natural), criado em 1818, no Rio de Janeiro; e o Museu Paraense Emilio Goeldi, criado em 1866, em Belém, Pará, são exemplos do movimento dos museus e prol da consolidação das ciências no Brasil.

\section{Museus e Centros de Ciência no século XX: sistemas de comunicação, aprendizagem e divulgação científica}

Durante o século XX, mudanças no conceito e nos objetivos da instituição "museu" deram origem a novas abordagens comunicativas nesses espaços. Tradicionalmente voltado para as coleções e a pesquisa, um importante redirecionamento no foco de trabalho dos museus foi uma maior preocupação em se dirigir de forma mais eficiente a um público amplo e diversificado, e a estabelecer uma relação mais estreita com as comunidades locais.

Os museus de ciência foram pioneiros na utilização de novas estratégias comunicativas. Na primeira metade do século, o Deutsches Museum, Alemanha (inaugurado em 1903) e o Palais de la Decouverte, na França (inaugurado em 1937), começaram a adotar estratégias de mediação que são usadas até hoje.

O Deutsches Museum desejava tornar a ciência e a tecnologia compreensíveis para o cidadão comum, através da introdução de novas formas de apresentação tais como 
exposições participativas, experiências ativadas por visitantes e/ou conduzidas por mediadores. Oskar von Miller, diretor do Museu na época, fazia uso extensivo de demonstrações, modelos seccionados, diagramas, tabelas, desenhos, linhas de tempo e/ou qualquer outro recurso museográfico que ajudasse na compreensão do visitante sobre os objetos da exposição. As legendas não continham o jargão dos cientistas e curadores. Miller também "evitava vitrines de vidro o quanto fosse possível, e a equipe de atendimento do museu era composta, sobretudo, de demonstradores e mediadores, em detrimento de guardas de sala" (Studart, 2006, apud Alexander, 1983: 353-4).

Na segunda metade do século, a abertura do Exploratorium em São Francisco em 1969 revolucionou a noção de interatividade nos espaços museológicos. As teorias educativas vigentes (em especial a do "construtivismo") encontram nos centros de ciência um local de experimentação e estudo.

O espaço museal passa a ser considerado um "sistema de comunicação" (Schiele, 2001; Valente, 2003:40), no qual elementos diversos entram em pauta nessa relação: o objeto, o espaço museal, o público, os profissionais que planejam as exposições, o conteúdo temático, os mediadores-intérpretes, entre outros. Esta relação específica que se realiza no espaço museal precisa ser "negociada" entre os diferentes atores. Os estudos de recepção, pesquisas de público e de avaliação começam a ser realizados para dar suporte a esta "negociação" entre os profissionais dos museus e o público. 0 entedimento do museu como um espaço de educação não formal, onde a aprendizagem se dá de forma livre e associada aos interesses de cada um, também abre um amplo campo de estudos sobre a natureza da aprendizagem nos espaços museais.

Marandino (2001), em sua tese de doutorado, cita a autora inglesa HooperGreenhill, especialista em educação e comunicação em museus, mencionando que essa pesquisadora considera duas abordagens principais de comunicação nas 
exposições: a abordagem transmissora e a abordagem cultural. Hooper-Greenhill faz uma revisão da literatura sobre os processos comunicativos nos museus, afirmando que o modelo transmissor é o mais usado nesses espaços. Esse modelo entende a comunicação "como um processo de concessão e de envio de mensagens e transmissão de idéias, de uma fonte de informação para um receptor passivo", com objetivos de "controle" (Hooper-Greenhill, 1994:16).

Por outro lado, na perspectiva da abordagem cultural, a realidade é moldada por meio de uma negociação contínua. Nesse caso, a comunicação é vista como um processo de troca e de participação. As pesquisas de público com base na abordagem cultural tornam-se fundamentais para compreender como o visitante constrói o sentido para si e quais as implicações disso para o planejamento das atividades nos museus (Hooper-Greenhill, 1994:17). A pesquisadora britânica faz uma crítica aos profissionais de museus responsáveis pelo planejamento de exposições, afirmando que grande parte dessa atividade ainda é elaborada sem levar em conta o público que irá visitá-las.

Após a Segunda Guerra Mundial, a afirmação social da ciência e da tecnologia no mundo contemporâneo coloca a ciência em um novo patamar. Torna-se crucial o modo pelo qual a sociedade percebe a atividade científica e absorve seus resultados, bem como os tipos e canais de informação científica a que tem acesso (Albagli, 1996: 396). Foi nesse contexto que afloraram iniciativas orientadas para a popularização da ciência e da tecnologia.

A divulgação científica supõe uma "tradução", ou "reinterpretação", de conteúdos expressos em linguagem especializada, técnica, acadêmica, para uma forma de expressão acessível ao público leigo, não especializado, sobre aspectos da ciência no mundo contemporâneo. De acordo com Albagli (1996: 397), a divulgação científica abarca questões de ordem cívica (desenvolvimento de uma opinião pública informada sobre os impactos do desenvolvimento científico e tecnológico 
sobre a sociedade), de mobilização popular (participação da sociedade na escolha de opções tecnológicas e formulação de políticas públicas), e educacional (compreensão do público leigo a respeito do processo científico).

A mídia e também os museus e centros de ciência estão entre os principais meios de divulgação da ciência. Os museus, por serem espaços de educação não formal e sistemas complexos de comunicação, podem contribuir para despertar nos indivíduos o interesse e a curiosidade sobre os processos e temas científicos, oferecer informação acessível e promover uma maior familiaridade com assuntos relacionados à ciência e à tecnologia por meio de diversas abordagens comunicativas.

\section{Desafios para os museus e centros de ciência no século XXI: diversidade e responsabilidade cidadã}

Ao longo do século XX, vimos coexistir diferentes abordagens museográficas e comunicativas que ainda são amplamente usadas nos dias de hoje: exposições onde o foco principal está no objeto e outras onde o foco principal está na interação. São comuns exposições que enfatizam ideias, mensagens e temas usando abordagens comunicativas por meio de informação textual, mediação humana (intérpretes, guias, atores), recursos audiovisuais, jogos, etc. Encontramos museus de ciência onde a ênfase é dada em aspectos históricos por meio da coleção e outros em que o foco é direcionado a aspectos educativos e/ou na divulgação da ciência e da tecnologia. Existem também aqueles em que todas essas abordagens estão presentes ao mesmo tempo. No século XXI, podemos dizer que começa a se firmar uma tendência de colocar o sujeito (visitante-usuário do museu) no centro da exposição (ou programas) e, a partir dele, desenvolver uma apresentação que desperte o seu engajamento com o material exposto e a realidade que o cerca. 
Gostaria agora de abordar, neste artigo, algumas questões fundamentais para a atividade dos profissionais dos museus. Não tenho aqui a pretensão de responder todas estas perguntas, mas sim levantar o debate.

\section{Com que concepção de museu, educação, história da ciência e divulgação científica estamos trabalhando? Como esses conceitos se articulam no contexto do museu?}

É preciso ter clareza que as ações do museu (e seus produtos) dependem diretamente de como entendemos o papel dessas instituições no mundo contemporâneo, como concebemos educação, divulgação científica e história no contexto museal, e o quanto somos capazes de articular essas áreas com o nosso conceito de museu, sem perder de vista o compromisso social da instituição.

O Instituto Brasileiro de Museus / Ibram trabalha com uma definição de instituição museológica que enfatiza as funções e responsabilidades do museu no mundo contemporâneo:

- o trabalho permanente com o patrimônio cultural, em suas diversas manifestações;

- a presença de acervos e exposições colocados a serviço da sociedade com o objetivo de propiciar a ampliação do campo de possibilidades de construção identitária, a percepção crítica da realidade, a produção de conhecimentos e oportunidades de lazer;

- a utilização do patrimônio cultural como recurso educacional, turístico e de inclusão social;

- a vocação para a comunicação, a exposição, a documentação, a investigação, a interpretação e a preservação de bens culturais em suas diversas manifestações;

- a democratização do acesso, uso e produção de bens culturais para a promoção da dignidade da pessoa humana; 
- a constituição de espaços democráticos e diversificados de relação e mediação cultural, sejam eles físicos ou virtuais. (Sistema Brasileiro de Museus, 2005)

Nas exposições dos museus de ciência ou de história das ciências a ênfase é dada nos grandes cientistas, suas invenções e descobertas, e nos "triunfos" da ciência. Por meio de narrativas, os museus constroem significados, reforçam identidades, e privilegiam certos aspectos em detrimentos de outros.

Não é comum encontrarmos exposições que consigam falar sobre o conhecimento científico relacionando também outros aspectos da cultura e da sociedade (aspectos filosóficos, econômicos, sociológicos, artísticos, entre outros). São muitas as questões sociais, éticas e políticas que envolvem as escolhas do que deve ou não ser exibido e falado em uma exposição de museu.

Bennett, pesquisador e curador do Museu de História da Ciência da Oxford University, em seu artigo "Museus e a História da Ciência" também comenta o "conflito de interesses" existente nas decisões sobre o que será ou não apresentado em uma exposição. Ele cita que, em muitos museus de história da ciência, os objetos não são usados para questionar e ampliar o entendimento sobre o passado, de forma que este ilumine o presente (Bennett, 2005: 606). 0 autor acredita que, de maneira geral, os objetos científicos, em muitos museus, são expostos para serem vistos mais como "ornamentos" do que como instrumentos pertencentes a uma atividade científica contextualizada em certo período da História.

Para Francisco Régis Ramos, historiador e professor na Universidade do Ceará, um museu de história deve exercer um papel crítico e atuante e ser capaz de partir do presente para se entender o passado:

Se pouco refletimos sobre os objetos [que nos cercam no dia a dia], a 
nossa percepção dos objetos expostos [em um museu] será também de reduzida abrangência. Sem o ato de pensar sobre o presente vivido, não há meios de construir conhecimento sobre o passado [...] Conhecer o passado de modo crítico significa, antes de tudo, viver o tempo presente como mudança.... (Ramos, 2004: 21)

Ramos busca nas idéias de Paulo Freire sobre educação, inspiração para se trabalhar o ensino de história no ambiente museal, principalmente no que se refere à ênfase dada por Freire no papel da educação para a cidadania. As correntes mais recentes da Museologia enfatizam a importância do papel social do museu, isto é, museus que colaborem com a inclusão social e cultural, com a formação de indivíduos criativos que possam - ao ampliar sua visão de mundo através do contato com os recursos do museu - exercer sua consciência crítica. A ideia de museu como um local aberto, livre de discriminações, atento às necessidades do seu público usuário, está em consonância com o pensamento de Freire sobre a importância do diálogo e do respeito no processo educativo. Ramos propõe uma pedagogia museal que ele chama de metodologia do "objeto gerador", criada a partir do método da "palavra geradora", de Paulo Freire:

O trabalho com o objeto gerador parte de exercícios que enfocam a experiência cotidiana e insere-se, portanto, na pedagogia da provocação, como diria Paulo Freire. A partir do vivido, é gerado o "debate de situações-problemas". Quando há comparações entre objetos do passado e os do presente, a noção de historicidade começa a ser trabalhada de modo mais direto. (Ramos, $2004:$ 34)

Nesse sentido, a proposta de trabalho com "objetos geradores" busca aprofundar as relações entre pesquisa histórica, ensino de história, museologia e pedagogia e contribuir para o debate sobre o ensino de história no espaço museológico. 
Valente também chama a atenção para o fato de que a falta de "atualização" da relação objeto-tempo, passado-presente, no museu, produz uma situação, no mínimo, anacrônica (Valente, 2003:43). Se o museu apenas mostrar o passado tal como era, sem procurar relacioná-lo ao presente, provavelmente não conseguirá obter um resultado fecundo em termos de uma reflexão útil para a realidade atual. Podemos então dizer que uma abordagem histórica simplesmente "cronológica" e "factual" em uma exposição histórica (seja de arte, ciência, história social, etc.), é uma abordagem que pouco contribui para a formação de cidadãos críticos.

Como o museu pode atender às necessidades e interesses de um amplo e diversificado público e exercer de forma efetiva o seu papel social?

No século XXI, um dos principais desafios das instituições museológicas é efetivar a sua devida contribuição social para o desenvolvimento da sociedade, em um mundo globalizado e ao mesmo tempo repleto de diversidades.

Thuillier, filósofo francês, questiona se a divulgação científica, tal como é feita, de fato ajuda a promover o aprendizado da ciência, ou a cultivar o espírito crítico, como crêem alguns. 0 verdadeiro saber, para ele, é aquele com o qual as pessoas são capazes de lidar no seu dia a dia: "Se o público não sabe lidar com o saber ou criticá-lo, estamos exibindo uma espécie de 'vitrine da ciência' - um saber que pode ser apenas contemplado..." (Thuillier, 1989:23).

O autor afirma que é necessário distinguir "vulgarização da ciência" e "cultura científica". Enquanto o primeiro conceito tem o foco na ciência contemporânea, os últimos resultados dos diferentes ramos da ciência e suas aplicabilidades para a sociedade, o segundo busca informar sobre o avanço do conhecimento científico ao longo da história e suas articulações com outras áreas (economia, filosofia, arte, política, etc.). Ambas as correntes, todavia, devem ser capazes de estimular a formação do "senso crítico": mostrar o saber científico de modo crítico; apresentar o significado dos resultados da ciência e suas implicações; mostrar não somente os 
triunfos da ciência, mas também suas dúvidas e lacunas; articular a ciência com outras áreas do conhecimento; todas essas questões devem ser levadas em consideração na concepção e planejamento de exposições em museus e centros de ciência.

Como colocar em prática essas ideias em um museu ou centro de ciência? Seria necessário, antes de tudo, que os profissionais dessas instituições tivessem uma atitude engajada, aberta e participativa frente ao seu papel educativo e social.

Com a finalidade de ajudar o cidadão a formar um juízo em relação a assuntos científicos diversos e a exercer seu espírito crítico, Thuillier sugere:

\footnotetext{
Para os problemas importantes [da humanidade], não há solução neutra: os problemas são sempre mais complicados do que o modelo científico. A saída talvez consista em visar não a objetividade, a neutralidade, mas em fazer várias pessoas, com pontos de vistas variados, falarem sobre um assunto. (Thuillier, 1989:23)
}

Pontos de vistas variados; diversidade; estímulo ao senso crítico; abertura; respeito a diferentes opiniões; confronto de ideias; contextualização cultural e histórica; olhares multidisciplinares; consciência cidadã; estas e outras estratégias e valores devem estar presentes nas exposições dos museus, caso queiramos que estes espaços sejam promotores da cidadania.

Em 2003, membros brasileiros do Comitê de Educação e Ação Cultural do ICOM Conselho Internacional de Museus (CECA-Brasil) prepararam um documento para ser apresentado na Conferência Anual do CECA no México, sobre o tema "Conceitos educacionais que moldam as realidades no museu: missão possível!”. O referido documento do CECA-Brasil (Studart, 2003) intitulou-se "Conceitos que transformam o museu, suas ações e relações". Este texto recebeu uma forte 
aprovação dos colegas presentes no encontro. Alguns conceitos transformadores da realidade interna e das ações das instituições museais foram apontados: preocupação com a cidadania, inclusão social, diversidade cultural, tolerância, solidariedade, participação, interação, interdisciplinariedade, curadoria conjunta, produção cultural museal, e responsabilidade social.

O texto, realizado coletivamente pelos membros do CECA-Brasil, enfatiza que os museus devem trabalhar na perspectiva do exercício da cidadania. A complexidade de funções e as responsabilidades sociais que o museu deve as sumir neste novo século exigem do profissional de museu uma atenção permanente e reflexões sobre as mudanças no meio em que vive, assim como sobre os interesses e necessidades do público.

Uma questão que se coloca para os atuais museus de ciência é, principalmente, como conjugar educação, divulgação científica e história da ciência em seus espaços. Citarei dois exemplos de instituições estrangeiras, na Inglaterra e na França, que buscam colocar em prática ações e estratégias que vêm sendo defendidas por especialistas em diversos artigos e livros.

O Science Museum, em Londres, adota a "diversidade" para lidar com essa questão. Lá, coexistem exposições e atividades dedicadas a diferentes temas e abordagens, acontecendo simultâneamente. Por exemplo, "Launch Pad" e "Flight Lab", exposições interativas, abordam conceitos e experimentos relacionados à ciência e à tecnologia de forma lúdica e com objetivos claramente educativos. Exposições temporárias, como "Big Bang", buscaram tratar de questões ligadas à ciência atual e à divulgação científica. Outras exposições, de longa duração, colocam as coleções do museu em foco, como "The Secret Life of the Home" e "Science in the 18th Century": a primeira apresenta, de forma acessível e lúdica, diversos objetos que fazer parte do lar e suas utilidades; a segunda, mais tradicional, apresenta em vitrines instrumentos científicos de rara beleza produzidos em épocas passadas, 
deixando clara a existência de uma relação entre ciência, tecnologia, arte e design. Além da diversidade de exposições, o Science Museum também adota diversas estratégias de mediação, como palestras, demonstrações, teatro, presença de "explainers" nas exposições interativas (nome dado aos mediadores nesses espaços), utilização de terminais de computadores, projeção de filmes, painéis explicativos, sítios eletrônicos como o "Ingenious" (que traz imagens e pontos de vistas diferentes, visando criar um debate sobre ciência e cultura), todos contribuindo para atender à diversidade de opiniões, estilos de aprendizagem e interesses de um amplo e variado público.

A Cité des Sciences et de l'Industrie - Universcience, o monumental centro de ciências francês, localizado em Paris no parque La Villette, além de exposição interativa de longa duração ("Explora”), de exposição especificamente planejada para o público infantil ("La Cité des Enfants") e de exposições temporárias sobre temas diversos, possui outros espaços que têm como foco principal apresentar a ciência contemporânea e seus impactos, como "Science Actualité" (exposição e sítio eletrônico) e "Cité de la Santé" (um ambiente dedicado a questões relativas à saúde). A Cité des Sciences et de l'Industrie não possui coleções de equipamentos e instrumentos científicos, como o Science Museum. Mas procura refletir sobre ciência no contexto da cultura, e enfatizar questões relativas à divulgação científica e educação em ciências.

Uma das principais críticas aos centros de ciência do tipo "hands-on", espalhados por todo o mundo, refere-se à falta de contextualização dos aparatos científicos e relação com a cultura e a realidade local onde estão inseridos. Hoje em dia, estudos de público e avaliação que investigam a aprendizagem em museus apontam para a necessidade de que os módulos expositivos nesses espaços façam ligações com o cotidiano, a fim de que as pessoas possam estabelecer associações com o mundo que as circundam. 
As instituições acima citadas (o Science Museum e a Cité des Sciences et de l'Industrie - Universcience) foram selecionadas pelo fato de serem dois ótimos exemplos de utilização de diversas idéias defendidas no campo dos museus e centros de ciência. Esses espaços recebem grande aporte de recursos financeiros do Governo em seus respectivos países (Reino Unido e França), apoio de patrocinadores, entre outras fontes de renda, para realizar seus programas e atividades. Estas instituições têm papel estratégico (portanto, político) no conjunto das ações educativas, culturais e de divulgação da ciência.

Não devemos, todavia, vincular a questão da pertinência das ações e competência das estratégias adotadas a uma questão financeira. Nem, tampouco, reduzir a uma questão de recursos humanos. Temos, no Brasil, excelentes profissionais de museus, competentes e criativos, capazes de desenvolver práticas museais inovadoras, e agências de fomento que trabalham com seriedade dentro de uma política científica, cultural e educacional. Podemos citar iniciativas exemplares em nosso país, como o projeto de popularização da ciência “Ciência Móvel”, do Museu da Vida/COC/Fiocruz, inspirado no Museu de Ciências e Tecnologia da PUC/RS, Porto Alegre; o pioneiro "Projeto Clicar" de inclusão digital da Estação Ciência (São Paulo); a premiada exposição multimídia sobre nanotecnologia - "Nanoaventura" desenvolvida pelo Museu Exploratório de Ciências da Universidade de Campinas/UNICAMP, que utiliza um conceito de interatividade em equipe para estimular a compreensão da nanotecnologia; o Espaço Ciência em Recife, com suas diversas atividades de arte e ciência, inclusão e preservação ambiental; a criação da ABCMC - Associação Brasileira de Centros e Museus de Ciência, uma associação que promove a articulação entre instituições e profissionais da área no Brasil, entre outras iniciativas.

Gestores do Instituto Brasileiro de Museus / Ibram apontam para a necessidade de se construir, na atualidade, modelos democráticos de gestão cultural. Um dos desafios atuais é, segundo eles, o encontro de "um ponto de equilíbrio dinâmico, no 
qual a participação da iniciativa privada, das comunidades populares e dos movimentos sociais não implique a exoneração do Estado do papel que lhe cabe na preservação da memória e na garantia do caráter público das ações culturais" (Storino et al., 2007).

Concluindo, museus e centros de ciência possuem missão e objetivos específicos, mas também amplos e ousados e, portanto, essas instituições devem definir, com clareza, planejamento acurado, que lugar almejam ocupar entre os equipamentos culturais e educativos das cidades que fazem parte, que serviços desejam oferecer para os diversos públicos, que resultados esperam alcançar, o que priorizar, e "como fazer" para atingir essas metas. E conscientes do seu papel social, cultural e educativo, desenhar as estratégias necessárias para se tornarem verdadeiramente participativas na formação de uma sociedade mais esclarecida e articulada.

\section{REFERÊNCIAS}

ALBAGLI, Sarita (1996) Divulgação Científica: informação científica para a cidadania? Ciência da Informação. IBICT. Brasília.Set./Dez. v.25, n.3, p.396-404.

ALEXANDER, Edward P. (1983). Museum's Masters. Their Museums and Their Influence. Nashville, Tennessee: American Association for State and Local History.

BENNETT, Jim (2005). "Museums and the History of Science". ISIS. Chicago. Dec. vol.96, n.4, p.602-608.

CAZELLI, Sibele; MARANDINO, Martha e STUDART, Denise C. (2003) "Educação e Comunicação nos Museus de Ciência: aspectos históricos, pesquisas e prática". In: Martha Marandino; Guaracira Gouvêa; Maria Cristina Leal. (Org.). Educação e Museu: a construção social do caráter educativo dos museus de ciência. Rio de Janeiro: Editora Access, p. 83-106.

DANTES, Maria Amélia Mascarenhas (2005) "As Ciências na História Brasileira". Ciencia e Culura. [online]. São Paulo. Jan./Mar. vol.57, no.1, p.26-29. Available from World Wide Web: $\quad<$ http://cienciaecultura.bvs.br/scielo.php?script=sci_arttext\&pid=S000967252005000100014\&lng=en\&nrm=iso>

HOOPER GREENHILL, Eileen [Org.] (1994). The Educational Role of the Museum. London: Routledge.

KUHLMANN JÚNIOR, M. (2001) As Grandes Festas Didáticas: a educação brasileira e as exposições internacionais (1862-1922). Bragança: Editora da Universidade de São Francisco. 
LOPES, Maria Margareth (2003) "Museus e Educação na América Latina:o modelo parisiense e os vínculos com as universidades". In: Martha Marandino; Guaracira Gouvêa; Maria Cristina Leal. (Org.). Educação e Museu: a construção social do caráter educativo dos museus de ciência. Rio de Janeiro: Editora Access, p.63-82.

MARANDINO, Martha (2001). O Conhecimento Biológico nas Exposições de Museus de Ciência: análise do processo de construção do discurso expositivo. Tese (Doutorado) Faculdade de Educação, Universidade de São Paulo.

PRIMON et al. (2000) "História da Ciência: da Idade Média à Atualidade". Revista Científica Psicólogo Informação. São Paulo. Vol.1, n.4, p.35-51. Dez.

RAMOS, Francisco Regis Lopes (2004) A Danação do Objeto. O Museu no Ensino de História. Chapecó: Argos.

STORINO, Claudia; BRAGA, Eneida; NASCIMENTO Jr., José ; CHAGAS, Mario (2007). "Museus: sob nova direção". Jornal do Brasil. 14 de Abril de 2007.

STUDART, Denise C. [Org.] (2003). "Conceitos que transformam o Museu, suas Ações e Relações" (Dossiê CECA-Brasil). Musas Revista Brasileira de Museus e Museologia. Rio de Janeiro. v. 1, p. 41-48.

STUDART, Denise C. (2006). "Exposições Participativas e Educativas em Museus". Cadernos Paulo Freire. Museu do Ceará. Secretaria da Cultura do Estado do Ceará. Expressão/CBL:Fortaleza.

THUILLIER, Pierre (1989). "O Contexto Cultural da Ciência”. Entrevista. Ciência Hoje, vol.9, n. 50. p.18-23.

VALENTE, Maria Esther (2003) "A Conquista do Caráter Público dos Museus". In: Martha Marandino; Guaracira Gouvêa; Maria Cristina Leal. (Org.). Educação e Museu: a construção social do caráter educativo dos museus de ciência. Rio de Janeiro: Editora Access, p.21-45.

\section{Sítios eletrônicos consultados}

Associação Brasileira de Centros e Museus de Ciência: http://www.abcmc.org.br

Exposição Nanoaventura, Museu Exploratório de Ciências:

http://www.mc.unicamp.br/nanoaventura/

La Cité des Sciences et del'Industrie - Universcience: http://www.cite-sciences.fr

Projeto Clicar, Estação Ciência: http://www.projetoclicar.org.br

Science Museum: http://www.sciencemuseum.org.uk

Sistema Brasileiro de Museus: http://www.museus.gov.br

Artigo recebido em janeiro de 2012. Aprovado em março de 2012 